\title{
Advances in the Diagnosis and Magagement of Eustachian Tube Dysfunction
}

\author{
Mario Milkov \\ Department of Dental Materials Science and Propaedeutics of Prosthetic Dental Medicine, \\ Faculty of Dental Medicine, Professor Paraskev Stoyanov Medical University of Varna, Varna, Bulgaria
}

\begin{abstract}
This concise review provides up-to-dated information about the recent achievements in the diagnostic work-up and management of Eustachian tube dysfunction, a common disorder in childhood and adulthood as well. The role of modern image diagnosis and balloon dilatation of the Eusstachian tube is emphasized. Integrated efforts of interdisciplinary clinical teams consisting of otorhinolaryngologists, radiologists, maxillo-facial surgeons, otoneurologists and other specialists are needed to meet the diagnostic and surgical challenges of this pathology.
\end{abstract}

Key words: Eustachian tube dysfunction, diagnosis, drug therapy, surgery

\section{LIST OF ABBREVIATIONS}

3D-CT - tridimensional computer tomography

BET - balloon Eustachian tuboplasty

CT - computer tomography

DETD - dilatory Eustachian tube dysfunction

EET - endonasal Eustachian tube dilatation

ET - Eustachian tube

ETBD - Eustachian tube balloon dilatation

ETS - Eustachian tube score

ETD - Eustachian tube dysfunction

ETDQ - Eustachian tube dysfunction questionnaire

EDTQ-7 - seven-item Eustachian tube dysfunction questionnaire

MRI - magnet resonance imaging

NNMA - nasal-noise masking audiometry

OSA - obstructive sleep apnea

PET - patulous Eustachian tube

SNOT - sino-nasal outcome test

TMM - tubomanometry

\section{Introduction}

Eustachian tube (ET) connects the nasopharynx with the middle ear cavity. ET is a complex and inaccessible structure, which maintains middle ear ventilation to facilitate transmission of sound from the tympanic membrane to the cochlea. ET lumen is lined with epithelial cells and coated with a viscous fluid. This normally closed lumen is surrounded by cartilage and periluminal mucosal tissue [1]. Several craniofacial muscles such as $m$. tensor veli palatini and $m$. levator veli palatini are attached to these soft tissue elements. ET key function is to ensure middle ear ventilation. This conduit opens in a physiologically complex and poorly understood manner to provide ventilation to the middle ear, and so equalize middle ear and ambient pressures.

Eustachian tube dysfunction (ETD) is a syndrome with a constellation of signs and symptoms of pressure dysregulation in the middle ear [2]. Athough $m$. tensor veli palatini plays a major role in ET opening, the reduced activity of $m$. levator veli palatini may be related to ETD [3]. In a strict sense, ETD is a failure to perform at least one of ET functions (to protect the middle ear from sources of disease, to ventilate the middle ear, and to help drain secretions away from the middle ear [4]. Three subtypes of ETD are defined: dilatory (DETD), baro-challengeinduced and patulous (PET) [2]. DETD is failure to open and ventilate the middle ear while in PET, there is failure of ET closure [5]. DETD is divided into functional obstruction, dynamic dysfunction (muscular failure), and anatomical obstruction [2]. 
Compromised ventilation results in inflammatory middle ear disorders. Patients suffering from ETD typically present with complaints of hearing loss and chronic or recurrent sensation of plugged ear. Findings of ETD can include serous effusion, conductive hearing loss (on tuning fork or audiometric testing), or negative middle ear pressure (on pneumatic otoscopy or tympanometry). Later on, there may be ETD sequelae such as retraction pockets, perforations, chronic drainage or cholesteatoma [5]. ETD can lead to impaired quality of life due to persistent sensation of ear fullness, ear pain, and inability to tolerate air travel or scuba diving.

It is suggested that normal newborn hearing could be attributed to persistence of middle ear effusion and predict poor ET function manifested as recurrent otitis media or otitis media with effusion in the first year of life [6]. Immediate ETD is a relatively common complication in children with adenotonsillar hypertrophy following adenotonsillectomy that necessitates properly planning the postoperative care and management [7].

The role of endotoxins of Gram-negative microorganisms and endothelial dysfunction in the etiology and pathogenesis of ETD, exudative otitis media, and the related complications of sensorineural hearing impairment is considered for the first time in 2012 [[8].

\section{Diagnosis of ETD}

There exists a variety of contemporary methods for precise diagnosis of EDT. Here belong the comprehensive clinical examination, otoscopy, including pneumatic otoscopy, audiometry, tympanometry, tubomanometry, sonotubometry, active anterior rhinomanometry, flexible endoscopy of epipharynx, videonasopharyngoscopy, computer tomography (CT), high-resolution $\mathrm{CT}$, spiral $\mathrm{CT}$ or tridimensional CT (3D-CT), microscopic inspection, and microbiological culture examination.

The results from a narrative systematic review of relevant articles searched in MEDLINE, EMBASE, BIOSIS and the Cochrane Library demonstrate that no single test of ET function could be considered a 'gold standard' for ETD diagnosis [9]. However, there is some evidence that diagnostic accuracy can be improved by combining the results of different objective tests and patient-reported outcome measures.
Within a combined, prospective, retrospective clinical study at a tertiary referral center, physical examination, history, tympanometry, audiometry, and TMM as well as EDTQ-7 are used as diagnostic tests in healthy subjects and patients with chronic obstructive ETD [10]. ETS-7, with a cutoff point of $\leq 7$ is a valid and reliable diagnostic instrument in adult patients with this pathology. An inflammation four-step scale based on digital video clips obtained during diagnostic rigid endoscopy can be used for DETD detection with a high level of consistency [11].

Concomitant ETD is diagnosed in 94 out of 295 infants with obstructive sleep apnea (OSA) aged between 3 and 24 months (in $31,86 \%$ of the cases) [12]. ETD prevalence amounts to $32 \%$ in OSA infants while it varies between $4 \%$ and $7 \%$ in the general pediatric population.

\subsection{ETDQ and ETDQ-7}

Patient's symptoms can be evaluated by means of Eustachian tube dysfunction questionnaire (ETDQ). A complex of methods such as active anterior rhinomanometry, audiometry, tympanometry and three-dimensional CT in 82 ETD patients are made use of [13]. A concomitant pathology of the paranasal sinuses, nasal cavity, and nasopharynx is established in $96,3 \%$ of these patients. There are nasal breathing difficulties in $62 \%$ of the cases.

E. D. McCoul et al. [14] develop and perform initial validation of the seven-item ETDQ (ETDQ7), a disease-specific instrument to assess symptoms with respect to ETD in 50 consecutive adult ETD patients and 25 control subjects. ETDQ-7 values and discriminative power are estimated in 39 patients with obstructive ETD, eight pateints with PET, and and 22 healthy controls using the Cronbach $\alpha$ coefficient [15]. However, ETDQ-7 is unable to discriminate between patients with obstructive ETD and PET.

\subsection{TMM and sonoturbometry}

Tubomanometry (TMM) initially described by Estŭve as a routine diagnostic tool for chronic obstructive ETD is evaluated in 215 healthy subjects within a combined prospective and retrospective clinical study [16]. A R-value $\leq 1$ indicates a regular ET function, a R-value $>1$ shows a delayed ET opening, and no definable R-value means no detectable ET opening. 
The rates of restricted opening or blocked ET under pressures of 30, 40, and 50 mbar by TMM testing are $76.19 \%, 66.7 \%$, and $57.97 \%$ in otitis media with effusion patients and $10 \%, 5 \%$, and $0 \%$ in control subjects, respectively ( $\mathrm{p}<0.05$ for all pressure groups) [17].

ETD is diagnosed by sonotubometry in $25 \%$ of Meniere's disease patients [18]. ETD incidence in four stages of Meniere's disease is the following: $0 \%$ in stage one, $40 \%$ in stage two, $38 \%$ in stage three, and $50 \%$ in stage four. ETD treatment can prevent Meniere's disease patients' hearing impairment.

A method for comparing the accuracy of sonotubometry and tympanometry for a definitive measure of ET opening assignments by swallowing was described [19].

\subsection{CT and MRI}

$\mathrm{CT}$ and magnet resonance imaging (MRI) are best suited to identifying features associated with obstructive ETD or PET, however, contrast enhanced radiographs and scintigraphy only provide true assessments of ET function [20].

ET movement during sniffing is visualized using a 320-row area detector CT scanner (Aquilion ONE, Toshiba) in four patients with patulous ET [21]. At the start of sniffing, the cartilaginous ET portion closes from the isthmus towards the pharynx. Various patterns of ET closure during sniffing in PET patients are demonstrated for the first time indicating that this method is useful for ETD evaluation. A functional multislice spiral CT protocol for ET examination in 23 patients with unilateral conductive hearing loss and ETD is elaborated [22]. ET cartilaginous portion opens partially and closes completely in nine patients while ten patients present with steady changes in this region. This method confirms the cause of conductive hearing loss and optimally defines a treatment policy.

\subsection{Other diagnostic tests}

In an observational, contemporary, cross-sectional study, the variation in middle ear pressure during ET function tests such as Valsalva maneuver, sniff test, and Toynbee maneuver was assessed in normal subjects and in patients with mild and moderate/ severe tympanic retraction [23]. The greatest variation occurs in ears with moderate/severe retraction. The results from a prospective case series study of
76 ears demonstrate that Valsalva CT maneuver consistently allows visualization of the lumen of the distal one-third of cartilaginous ET in $94 \%$ of ears with no ET-related complaints and could localize the symptomatic obstructive ETD [24].

Nasopharyngeal reflux may have a role in ETD pathogenesis as the latter is more likely associated with a higher number of nasopharyngeal reflux events $(\mathrm{p}<0,002)$ and higher reflux finding score $(\mathrm{p}$ $<0,001)$ in adult ETD patients than in control subjects [25]. The comparative study of ET functions in normal and diseased ears with tympanometry and videonasopharyngoscopy indicates the superiority of the second diagnostic method [26]. Slow motion video analysis of ET dynamics is a useful tool for further understanding ETD pathophysiology.

The functions of the paratubal muscles are evaluated using electromyography in ten patients with chronic unilateral ETD under the view of a $30^{\circ}$ endoscope or fiberoptic laryngoscope [3]. ET swallow test and dynamic slow motion video endoscopy are performed in 100 clinically normal middle ears of adults undergoing rigid nasal endoscopy [27]. The second method over-diagnoses ETD when used as a standalone test. In combination with other tests, however, it provides valuable information regarding the structural and functional status of ET pharyngeal end.

The analysis of the nasal-noise masking audiometry (NNMA) as a clinical diagnostic tool in PET patients displays a larger masking effect than in normal subjects in the low-frequency region [28].

\section{Treatment of ETD}

Retrospective searches in 12 databases up to October 2012 for published and unpublished studies in English identify 19 studies dealing with interventions for adult ETD [4]. There are very short-term improvements in middle ear function in patients receiving directly applied topical decongestants or a combination of antihistamine and ephedrine. Eustachian tuboplasty (seven case series), ETBD (three case series), myringotomy (two case series), directly applied topical steroids (one case series) and laser point coagulation (one controlled beforeand-after study) are associated with improved outcomes.

A successful application of the Modified Butyenko breathing technique is reported in a 28 -year old male soldier with ETD following swimming at depth [29]. 


\subsection{Drug treatment of ETD}

Numerous evidence-based therapy options are available for the treatment of impaired middle ear ventilation and otitis media, the main therapeutic approach being antibiotic treatment [30].

The results from the National Ambulatory Medical Care Survey and the National Hospital Ambulatory Medical Care Survey (2005-2010) show infrequent oral steroid usage for otitis media with effusion, ETD, and tympanic membrane retraction in children and adults in the USA, particularly in children [31].

\subsection{Surgery of ETD}

The systematic review of 14 studies comprising a total of 226 patients who have undergone surgical management for PET identifies the following most commonly reported techniques: ET plugging, PET placement and suture ligation [32]. Postoperative follow-up lasts between two and 60 months (mean, 20.6 months), overall symptom improvement varies between $22 \%$ and $100 \%$ (mean, $72.4 \%$ ) as a low incidence rate of minor complications is reported in nine studies.

\subsubsection{ETBD}

ETBD results in improved ear fullness and pressure in $71 \%$ of ETD patients followed-up for $26.3 \pm 3.6$ weeks [33]. There is persistent improvement in seven out of eight patients (in $87.5 \%$ of the cases) followed-up for a minimum of 34 months. This safe method is used for effective management of ETD patients [34]. It produces significant improvement in tympanogram values up to 15 months postoperatively [5].

In a retrospective cohort study of 21 patients, this new method constitutes a safe and very promising treatment option for ETD patients based on earlyoutcome analysis [35]. It shows initial success, indeed, but must undergo further evaluation with regard to evidence [30]. The successful ETBD application in 40 patients with symptomatic ETD refractory to medical management is proved by subjective improvement, impedance audiometry, R-value in TMM, ETS and the ability to perform a Valsalva maneuver one week, three and 12 months postoperatively [36].

The retrospectively analysis of 66 children at a mean age of 8.12 years (range, 4-14 years) with chronic obstructive ETD who have undergone ETBD using the Bielefeld balloon catheter proves that there are no complications during surgery and clinical symptoms improve in more than $80 \%$ of the patients [37].

ETBD in 13 patients with bilateral ETD results in reduction of inflammatory epithelial changes and submucosal inflammatory infiltrate and thus contributes to clinical improvement in ET function [38].

ETBD or microdebrider Eustachian tuboplasty are feasible treatment options for patients with refractory ETD as an alternative to tympanostomy tube placement [39]. PET repair by shim insertion or fat graft reconstruction within ET lumen orifice may be effective.

\subsubsection{BET}

The preoperative high-resolution CT scan of the temporal bone is not suitable to predict intraoperative or postoperative difficulties of BET [40]. The surgeon should be extremely cautious during balloon catheter insertion into ET and apply a device designed with a built-in stop mechanism preventing a too deep insertion.

During a retrospective cohort study, this procedure is applied in 622 patients with chronic obstructive ETD preoperatively assessed by TMM [41]. One year after treatment, ETS improves significantly in $73 \%$ of ears - from $3,13 \pm 2,47$ to $5,75 \pm 2,76$, while two years after treatment it does from $2,65 \pm 2,89$ to $6,26 \pm 3,07$. After five years, this improvement is significant in $82 \%$ of patients. Patients' subjective satisfaction is approximately $80 \%$.

Based on comprehensive literature analyses, the conclusion is drawn that although all publications claim that BET is a safe and very promising method offering a new approach for ETD management, the question whether or not preoperative CT scans are needed should be considered in each individual case [42].

A systematic review and meta-analysis of nine case series studies with 443 patients (642 ET) concerning the evidence on BET as a treatment modality for ETD indicates reduction of patient symptoms in ETD questionnaire $(p<0.001)$, postoperative tympanic membrane normalization, conversion of type B or type $\mathrm{C}$ into type A tympanograms, reduced mucosal inflammation, increased number of positive Valsalva test and Swallowing tests, ETS improvement, reduction in sino-nasal outcome test (SNOT)-22 score $(\mathrm{p}=0.001)$, and increased quality of life $(\mathrm{p}=0.001)$ [43]. 


\subsubsection{EET}

The retrospective analysis of 33 children having undergone EET reveals relief of patients' complaints, e.g. otorrhea, otalgia, and hearing loss in most cases and absence of complications [44]. However, TMM does not show improved ET function or favourable postoperative changes in the R-data.

Usage of the uni- or bilateral EET utilizing a balloon catheter proves to be a minimally invasive, feasible and effective option in 217 patients with symptomatic chronic obstructive ETD [45]. The mean pre-treatment ETS value significantly improves from $2,23 \pm 1,147$ to $2,68 \pm 1,011$ ones year after EET.

\subsubsection{Other modern surgery}

The application of a central inset pharyngeal flap for correcting the persistent velopharyngeal incompetence after cleft palate repair in 28 patients leads to a significant improvement in ET function ( $p<$ 0,001 ) as assessed through otoscopic, tympanometric, and audiometric examinations [46].
In adult ETD patients, silicone nasal septal splints with integral airway are a more reasonable option than bilateral anterior Merocel nasal packs after septoplasty for isolated septal deviation because they allow inhalation through the nose and cause less ETD [47].

A total of 135 myringotomy and ventilation tube placement procedures are done in intants with OSA and concomitant ETD [12]. Of the 137 interventions for OSA treatment, 10 non-surgical $(45,5 \%)$ and 75 surgical interventions $(65,2 \%)$ do not require any further myringotomy and ventilation tube placement procedures afterward.

It has been suggested that bariatric surgery in obese patients can cause ETD symptoms, probably due to rapid weight loss and the consequent loss of peritubal fat [48].

\section{Conclusion}

The performance of effective diagnosis and adequate treatment of ETD in childhood and adulthood necessitates, obviously, integrated efforts of interdisciplinary clinical teams consisting of otorhinolaryngologists, radiologists, maxillo-facial surgeons, otoneurologists and other specialists.

\section{References}

1. Sheer FJ, Swarts JD, Ghadiali SN. Three-dimensional finite element analysis of Eustachian tube function under normal and pathological conditions. Med Eng Phys 2012; 34:605-16.

2. Schilder AG, Bhutta MF, Butler CC, Holy C, Levine LH, Kvaerner KJ, et al. Eustachian tube dysfunction: consensus statement on definition, types, clinical presentation and diagnosis. Clin Otolaryngol 2015; 40:407-11.

3. Chang KH, Jun BC, Jeon EJ, Park YS. Functional evaluation of paratubal muscles using electromyography in patients with chronic unilateral tubal dysfunction. Eur Arch Otorhinolaryngol 2013;270:1217-21.

4. Llewellyn A, Norman G, Harden M, Coatesworth A, Kimberling D, Schilder A, et al. Interventions for adult Eustachian tube dysfunction: a systematic review. Health Technol Assess 2014; 18:1-180, V-VI.

5. Williams B, Taylor BA, Clifton N, Bance M. Balloon dilation of the Eustachian tube: a tympanometric outcomes analysis. J Otolaryngol Head Neck Surg 2016; 45:13. doi: 10.1186/s40463-016-0126-6.

6. Chen JL. Newborn hearing screening may predict Eustachian tube dysfunction. Int J Pediatr Otorhinolaryngol 2015; 79:2099-103.

7. Choi JH, Yoon HC, Kim TM, Choi J, Park IH, Kim TH, et al. The immediate effect of adenotonsillectomy on Eustachian tube function in children. Int J Pediatr Otorhinolaryngol 2015; 79:1444-7.

8. Petukhova NA. Dysfunction of the Eustachian tube and endothelial dysfunction: the present view of the problem (Part 1). Vestn Otorinolaringol. 2012; (4):88-93 (Article in Russian).

9. Smith ME, Tysome JR. Tests of Eustachian tube function: a review. Clin Otolaryngol 2015; 40:300-11.

10. Schröder S, Lehmann M, Sauzet O, Ebmeyer J, Sudhoff H. A novel diagnostic tool for chronic obstructive Eustachian tube dysfunction - the Eustachian tube score. Laryngoscope 2015; 125:703-8.

11. Kivekдs I, Pöyhönen L, Aarnisalo A, Rautiainen M, Poe D. Eustachian tube mucosal inflammation scale validation based on digital video images. Otol Neurotol. 2015; 36:1748-52.

12. Robison JG, Wilson C, Otteson TD, Chakravorty SS, Mehta DK. Increased Eustachian tube dysfunction in infants with obstructive sleep apnea. Laryngoscope 2012; 122:1170-7.

13. Litovets TS, Litovets II, Krasnozhen VN, Mikharlov MK. Comprehensive diagnostics of the patients presenting with Eustachian tube dysfunction. Vestn Otorinolaringol 2013; (5):66-8 (Article in Russian).

14. McCoul ED, Anand VK, Christos PJ. Validating the clinical assessment of eustachian tube dysfunction: The Eustachian Tube Dysfunction Questionnaire (ETDQ-7). Laryngoscope 2012; 122:1137-41.

15. Van Roeyen S, Van de Heyning P, Van Rompaey V. Value and discriminative power of the seven-item Eustachian Tube Dysfunction Questionnaire. Laryngoscope 2015; 125:2553-6.

16. Schröder S, Lehmann M, Korbmacher D, Sauzet O, Sudhoff H, Ebmeyer J. Evaluation of tubomanometry as a routine diagnostic tool for chronic obstructive Eustachian tube dysfunction. Clin Otolaryngol 2015a; 40:691-7.

17. Liu P, Su K, Zhu B, Wu Y, Shi H, Yin S. Detection of Eustachian tube openings by tubomanometry in adult otitis media with effusion. Eur Arch Otorhinolaryngol 2016 Feb 19. doi: 10.1007/s00405-016-3938-0.

18. Kitajima N, Watanabe Y, Suzuki M. Eustachian tube function in patients with Meniere's disease. Auris Nasus Larynx 2011; 38:215-9. 
19. Swarts JD, Teixeira MS, Banks J, El-Wagaa J, Doyle WJ. A method to assess the accuracy of sonotubometry for detecting Eustachian tube openings. Eur Arch Otorhinolaryngol 2015; 272:2111-9.

20. Smith ME, Scoffings DJ, Tysome JR. Imaging of the Eustachian tube and its function: a systematic review. Neuroradiology 2016; 58:54356.

21. Yoshioka S, Naito K, Fujii N, Katada K. Movement of the Eustachian tube during sniffing in patients with patulous Eustachian tube: evaluation using a 320-row area detector CT scanner. Otol Neurotol 2013; 34:877-83.

22. Bodrova IV, Dobrotin VE, Kulakova LA, Fominykh EV, Pokoziǐ IIu, Lopatin AS. Conductive hearing loss caused by eustachian tube dysfunction according to the data of functional computed tomography. Vestn Rentgenol Radiol 2012; (1):4-8 (Article in Russian).

23. Canali I, Petersen Schmidt Rosito L, Siliprandi B, Giugno C, Selaimen da Costa S. Assessment of Eustachian tube function in patients with tympanic membrane retraction and in normal subjects. Braz J Otorhinolaryngol 2016 Apr 25. doi: 10.1016/j.bjorl.2016.01.010.

24. Tarabichi M, Najmi M. Visualization of the eustachian tube lumen with Valsalva computed tomography. Laryngoscope 2015; 125:724-9.

25. Brunworth JD, Mahboubi H, Garg R, Johnson B, Brandon B, Djalilian HR. Nasopharyngeal acid reflux and Eustachian tube dysfunction in adults. Ann Otol Rhinol Laryngol 2014; 123:415-9.

26. Chauhan B, Chauhan K. A comparative study of eustachian tube functions in normal and diseased ears with tympanometry and videonasopharyngoscopy. Indian J Otolaryngol Head Neck Surg 2013; 65(Suppl 3):468-76.

27. Augustine AM, Varghese L, Michael RC, Albert RR, Job A. The efficacy of dynamic slow motion video endoscopy as a test of Eustachian tube function. J Laryngol Otol 2013; 127:650-5.

28. Paradis J, Bance M. Assessment of nasal-noise masking audiometry as a diagnostic test for patulous Eustachian tube. Otol Neurotol. 2015; 36:e36-41.

29. Herron JB. The use of breathing techniques for the management of Eustachian tube dysfunction. J R Army Med Corps 2016 Jan 8 . doi: 10.1136/jramc-2015-000564.

30. Teschner M. Evidence and evidence gaps in the treatment of Eustachian tube dysfunction and otitis media. Laryngorhinootologie 2016; 95(Suppl 1):S136-54 (Article in German).

31. Bellmunt AM, Vila PM, Chen JX, Rosenfeld RM, Hackell JM, Shin JJ. Oral steroid usage for otitis media with effusion, Eustachian tube dysfunction, and tympanic membrane retraction. Otolaryngol Head Neck Surg 2016; 155:139-46.

32. Hussein AA, Adams AS, Turner JH. Surgical management of patulous Eustachian tube: A systematic review. Laryngoscope 2015; 125:2193-8.

33. Catalano PJ, Jonnalagadda S, Yu VM. Balloon catheter dilatation of Eustachian tube: a preliminary study. Otol Neurotol 2012; 33:1549-52. doi: 10.1097/MAO.0b013e31826a50c3.

34. Sudhoff H, Schröder S, Reineke U, Lehmann M, Korbmacher D, Ebmeyer J. Therapie chronisch obstruktiver Funktionsstörungen der Tuba Eustachii. HNO 2013; 61:477-82.

35. Gürtler N, Husner A, Flurin H. Balloon dilation of the Eustachian tube: early outcome analysis. Otol Neurotol 2015; $36: 437-43$.

36. Xiong $\mathrm{H}$, Liang M, Zhang Z, Xu Y, Ou Y, Chen S, et al. Efficacy of balloon dilation in the treatment of symptomatic Eustachian tube dysfunction: One year follow-up study. Am J Otolaryngol 2016; 37:99-102.

37. Maier S, Tisch M, Maier H. Balloon dilation of the Eustachian tube in pediatric chronic obstructive Eustachian tube dysfunction patients. HNO. 2015; 63:686-8, 690-4, 696-7 (Article in German).

38. Kivekдs I, Chao WC, Faquin W, Hollowell M, Silvola J, Rasooly T, et al. Histopathology of balloon-dilation Eustachian tuboplasty. Laryngoscope. 2015a; 125(2):436-41.

39. Adil E, Poe D. What is the full range of medical and surgical treatments available for patients with Eustachian tube dysfunction? Curr Opin Otolaryngol Head Neck Surg 2014; 22:8-15.

40. Abdel-Aziz T, Schröder S, Lehmann M, Gehl HB, Ebmeyer J, Sudhoff H. Computed tomography before balloon Eustachian tuboplasty - a true necessity? Otol Neurotol 2014; 35:635-8.

41. Schröder S, Lehmann M, Ebmeyer J, Upile T, Sudhoff H. Balloon Eustachian tuboplasty: a retrospective cohort study. Clin Otolaryngol. 2015b; 40:629-38.

42. Pau HW. Does balloon dilatation represent a breakthrough for Eustachian tube disorders - even in children? HNO 2015; 63:681-2,684-5 (Article in German).

43. Randrup TS, Ovesen T. Balloon Eustachian tuboplasty: a systematic review. Otolaryngol Head Neck Surg 2015; 152:383-92.

44. Jenckel F, Kappo N, Gliese A, Loewenthal M, Lörincz BB, Knecht R, et al. Endonasal dilatation of the Eustachian tube (EET) in children: feasibility and the role of tubomanometry (Estuve) in outcomes measurement. Eur Arch Otorhinolaryngol 2015; 272:3677-83.

45. Dalchow CV, Loewenthal M, Kappo N, Jenckel F, Loerincz BB, Knecht R. First results of Endonasal dilatation of the Eustachian tube (EET) in patients with chronic obstructive tube dysfunction. Eur Arch Otorhinolaryngol 2016; 273:607-13.

46. El-Anwar MW, Amer HS, Elnashar I, Khazbak AO, Khater A. Effect of central inset pharyngeal flap for velopharyngeal insufficiency on eustachian tube function. Laryngoscope 2015; 125:1729-32.

47. Yilmaz MS, Guven M, Buyukarslan DG, Kaymaz R, Erkorkmaz U. Do silicone nasal septal splints with integral airway reduce postoperative eustachian tube dysfunction? Otolaryngol Head Neck Surg 2012; 146:141-5.

48. Pascoto G, Abreu C, Silva ML, Weber R, Pignatari SS, Stamm A. The impact of acute loss of weight on eustachian tube function. Int Arch Otorhinolaryngol 2014; 18(4):376-9.

Address for correspondence:
Assoc. Prof. Mario Milkov, MD, PhD
Department of Dental Materials Science and Propaedeutics of Prosthetic Dental Medicine, Faculty of Dental Medicine
Professor Paraskev Stoyanov Medical University of Varna
84 Tsar Osvoboditel Blvd
Varna 9002
Bulgaria
Phone: $+359-888897403$
E-mail: mario.milkov@gmail.com

